OPEN ACCESS

Edited by:

Hans Thulesius,

Linnaeus University, Sweden

Reviewed by:

Samantha Rowbotham,

The University of Sydney, Australia

Erika Saliba Gustafsson,

Stanford University, United States

${ }^{*}$ Correspondence:

Annelies Colliers

annelies.colliers@uantwerpen.be

Specialty section

This article was submitted to Family Medicine and Primary Care,

a section of the journal

Frontiers in Medicine

Received: 02 July 2021 Accepted: 21 October 2021 Published: 01 December 2021

Citation:

Colliers A, Bombeke K, Philips H,

Remmen $R$, Coenen $S$ and

Anthierens S (2021) Antibiotic

Prescribing and Doctor-Patient

Communication During Consultations

for Respiratory Tract Infections: A

Video Observation Study in

Out-of-Hours Primary Care

Front. Med. 8:735276.

doi: 10.3389/fmed.2021.735276

\section{Antibiotic Prescribing and Doctor-Patient Communication During Consultations for Respiratory Tract Infections: A Video Observation Study in Out-of-Hours Primary Care}

\author{
Annelies Colliers ${ }^{1 *}$, Katrien Bombeke ${ }^{2}$, Hilde Philips ${ }^{1}$, Roy Remmen ${ }^{1}$, Samuel Coenen ${ }^{1,3}$ \\ and Sibyl Anthierens ${ }^{1}$ \\ ${ }^{1}$ Department of Family Medicine and Population Health (FAMPOP), University of Antwerp, Antwerp, Belgium, ${ }^{2}$ Skills \\ Laboratory, University of Antwerp, Antwerp, Belgium, ${ }^{3}$ Vaccine and Infectious Disease Institute (VAXINFECTIO) - Laboratory \\ of Medical Microbiology, University of Antwerp, Antwerp, Belgium
}

Objective: Communication skills can reduce inappropriate antibiotic prescribing, which could help to tackle antibiotic resistance. General practitioners often overestimate patient expectations for an antibiotic. In this study, we describe how general practitioners and patients with respiratory tract infections (RTI) communicate about their problem, including the reason for encounter and ideas, concerns, and expectations (ICE), and how this relates to (non-)antibiotic prescribing in out-of-hours $(\mathrm{OOH})$ primary care.

Methods: A qualitative descriptive framework analysis of video-recorded consultations during $\mathrm{OOH}$ primary care focusing on doctor-patient communication.

Results: We analyzed 77 videos from 19 general practitioners. General practitioners using patient-centered communication skills received more information on the perspective of the patients on the illness period. For some patients, the reason for the encounter was motivated by their belief that a general practitioner (GP) visit will alter the course of their illness. The ideas, concerns, and expectations often remained implicit, but the concerns were expressed by the choice of words, tone of voice, repetition of words, etc. Delayed prescribing was sometimes used to respond to implicit patient expectations for an antibiotic. Patients accepted a non-antibiotic management plan well.

Conclusion: Not addressing the ICE of patients, or their reason to consult the GP OOH, could drive assumptions about patient expectations for antibiotics early on and antibiotic prescribing later in the consultation.

Keywords: antibiotics, respiratory tract infections, video observation, reason for encounter, communication, primary care, general practice, out-of-hours care

\section{INTRODUCTION}

There is a growing problem of antibiotic resistance because of antibiotic overprescribing. Therefore, enhancing antibiotic prescribing quality is essential. Antibiotics are one of the most prescribed medications in out-of-hours $(\mathrm{OOH})$ primary care, mainly for respiratory tract infections (RTIs) (1). In Belgian $\mathrm{OOH}$ care, there is antibiotic overprescribing (e.g., over $75 \%$ of patients presenting 
with tonsillitis and over 50\% with bronchitis, sinusitis, and otitis media have been prescribed an antibiotic) and the overuse of non-guideline recommended antibiotics, which is in line with primary care during office hours (1). Also, in Norway and Sweden, there are no large differences during and outside office hours $(2,3)$. In the Netherlands, higher prescribing rates in $\mathrm{OOH}$ primary care were found, but with equal or even better quality compared with during office hours (4). In Iceland, a substantial number of patients with acute otitis media or pneumonia are prescribed broad-spectrum antibiotics in $\mathrm{OOH}$ primary care (5). In the United Kingdom, an increase in antibiotic prescribing outside compared with during office was seen in primary care $(6,7)$. And also in Danish $\mathrm{OOH}$, primary care, antibiotics are the most prescribed medications (8). Although many contacts during $\mathrm{OOH}$ consist of self-limiting RTIs, and general practitioners (GPs) feel that most contacts represent non-urgent problems, they struggle to prescribe antibiotics prudently $(9,10)$. Out-of-hours GPs see unknown patients in a time-pressured setting that lacks follow-up possibilities or diagnostic tools $(11,12)$.

The problem presentation of patients and the communication of GPs affect antibiotic prescribing (13-16). The problem presentation refers to the communication at the start of the consultation where patients present their problems, including the reason for the encounter and the ideas, concerns, and expectations (ICE) of the patients. It is initiated by an opening question, and typically part of the "agenda mapping" phase of the consultation, which normally ends when history taking starts (17-20). Agenda mapping is essential in patient-centered communication $(21,22)$. Considering the agenda of both the doctor and the patient and taking time to elicit the problems and concerns of the patient, leads to higher patient satisfaction, reduces late arising concerns, improves understanding, time management, treatment adherence, and better health outcomes $(20,23-26)$. In practice, addressing the ICE of the patient does not always feel natural for GPs (27). Using ICE needs to be approached delicately, context-sensitive and patient-specific. It has been part of the medical training of Belgian GPs for many years now.

The way patients present their problem has been shown to be a predictor of receiving an antibiotic, such as using a candidate diagnosis $(13,15,28)$ or discussing or justifying the need for a consultation $(29,30)$. GPs make assumptions about why the patient consults (31), and often overestimate patient expectations for antibiotics $(28,32)$. Research has shown that patients with an infection consult because of unpleasant symptoms, the perceived need for action, obtaining symptomatic treatment, or concerns about illness severity. Also, the need for assessment, information, or reassurance rather than expectations for antibiotics, are possible reasons to consult (33-35). Most expect a thorough examination and explanation for their symptoms (36). Soliciting patient expectations could lead to higher patient satisfaction and reduced antibiotic prescribing (37-39). But often, the patients do not voice their agenda, therefore keeping their needs hidden. One of the reasons is doctors quickly interrupting patients at the start of the consultation (40-45) or a lack of solicitation of this agenda (46). A Korean study in emergency care has shown that patients and their accompanying person do not only describe the problem but also discuss the reasonableness in their reason for encounter (47).

Despite a comparable quality of antibiotic prescribing during and outside office hours, GPs experience the decision to prescribe antibiotics differently in the $\mathrm{OOH}$ context. What remains unclear is how patients with RTIs communicate their reason to consult $\mathrm{OOH}$ primary care, how GPs and patients communicate about ICE and how this relates to (non-)antibiotic prescribing management and communication. A better understanding would enable to tailor future interventions to improve the antibiotic prescribing quality in this specific context.

Therefore, this study sets out to describe how patients present their problem and how GPs interact with this and elicit the ICE of patients, and in what possible ways this doctor-patient communication relates to antibiotic prescribing for RTIs in $\mathrm{OOH}$ care.

\section{METHODS}

\section{Study Context}

This study is part of the Better Antibiotic prescribing through Action Research (BAbAR) project, which uses participatory action research (PAR) to improve the quality of the antibiotic prescribing of GPs in the Belgian OOH primary care (48).

Videos were recorded during the day at weekends from the end of August until November 2018 in the Antwerp city GPs cooperative (GPC), Belgium. In this GPC, all 185 GPs of the region are involved in a rotation system in one location during all weekends and bank holidays and cover a population of about 186,000 patients.

\section{Study Design, Participants, and Data Collection}

Patients presenting in the $\mathrm{OOH}$ setting with infections were informed and invited by a medical student to participate. A small web camera was used, pointing at the GP and not the patient. The voices of the patients were captured. The GP was in charge of the camera. The researcher was not present in the consultation room. A maximum variation sample of GPs was used, to have a variety in sex and age. The GPs who were scheduled to work during the study period were invited to participate by email or telephone and received two cinema tickets as compensation. The GPs did not receive any additional communication training for this study. The GP, patient, and consultation characteristics were collected.

Some of the videos were used in a previous study for the purpose of elicitation interviews (31) and the complete study setup is described in a separate paper (49).

\section{Data Analysis}

All videos were transcribed verbatim. Where applicable, Jeffersonian transcription, as shown in Table 1, was used to capture more detail on distinctive elements such as computer use, pauses, emphasis, and non-verbal signs (50). We used Excel (Microsoft Corporation, Washington, United States) to support the data analysis. 
TABLE 1 | Used symbols (derived from Jeffersonian transcription).

\begin{tabular}{ll}
\hline Underlined text & Emphasizing \\
\hline (.) & Micropause usually $<0.2 \mathrm{~s}$ \\
$(\#$ seconds) & The time, in seconds, of a pause \\
$=$ & Continuation of speak \\
$(($ text)) & Annotation of non-verbal activity \\
$::$ & Prolongation \\
$><$ & Speeded talk \\
\hline
\end{tabular}

We used a combined deductive and inductive framework analysis with a descriptive approach (51). The analysis started with two data sessions with all authors to familiarize and emerge themselves in the data. In these sessions, $10 \%$ of the videos, with a range of cases (different GPs, different infections, antibiotics prescribed or not) purposefully selected by AC, were viewed to decide upon which recurring patterns of interaction would further lead the analysis. The team decided to investigate the problem presentation and how the GPs elicited the ICE concerning (non-)antibiotic prescribing for RTIs.

Then, an inductive approach was used to code $15 \%$ of the videos in sessions involving $\mathrm{AC}, \mathrm{SA}$, and $\mathrm{KB}$ (inductive component) (AC: GP; SA: social scientist, specialism: antibiotic prescribing behavior change; KB: GP, specialism: doctorpatient communication).

Subsequently, a framework was developed to organize the large amount of data based on the literature and the initial inductive analyses. It included parts of the Maastricht Historytaking and Advice Scoring list consisting of global items (Maas global) and Calgary-Cambridge Guides (15, 23, 52, 53). The MAAS-global and Calgary Cambridge Guides are instruments to obtain objective measures to rate, feedback, and judge doctor-patient communication. The framework is provided as Supplementary Material 1. The relevant elements of the consultation were charted by AC (deductive component), and notes, apparent communication skills, and interpretations were added.

From this framework, AC, SA, and $\mathrm{KB}$ inductively identified the relevant results and discussed and described the final results. In the discussion, we have interpreted our results and discussed the potential implications of our results on antibiotic prescribing.

\section{Ethics}

The study was approved by the Ethics Committee of the Antwerp University Hospital/University of Antwerp (reference number 17/08/089) and registered at ClinicalTrials.gov (NCT03082521). Permission for the video recordings was obtained from the Belgian Committee of Health of the Commission for the Protection of Privacy (SCSZG/18/067).

All the participating GPs and patients, who were eligible (presenting with an infection) and able (sufficient knowledge of the language), provided written informed consent. For patients under the age of 16 years, one of the parents or the legal guardian gave consent.

\section{RESULTS}

Out of 196 eligible patients with all types of infections, 152 (78\%) agreed to participate. For this study, 77 videos on RTIs from 19 GPs were included (exclusion of consultations on skin infections, urinary tract infections, genital infections, and gastroenteritis). More details are presented in Table 2.

We withheld three themes. Theme 1 shows how patients presented their reason to consult the $\mathrm{OOH}$ GP and how the GP elicited their perspective. Theme 2 shows how the concerns of the patients were expressed and/or handled. Theme 3 shows the lack of eliciting patient expectations and how delayed prescribing was used to accommodate expectations. Finally, theme 4 illustrates how the GPs communicated their treatment plan.

\section{Problem Presentation of the Patients}

In the first phase of the consultation, we looked at how the patients presented their reason to seek help during the weekend and how the GPs explored the ICE of the patients.

\section{Reasons of the Patient to Contact the GP on Call}

After the GP opened the consultation, most patients started by listing their symptoms and/or suggesting a diagnosis. This diagnosis could be a viral ["uh I have the flu and I would like euhm, you know, get some medication eventually” (GP15, female, 36y - P57, female, 23y, upper respiratory tract infection (URTI))] or bacterial diagnosis ["well, I thought: do I have pneumonia?” (GP3, female, 63y, P10, female, 67y, pneumonia)], or even multiple diagnoses ["I'm really flu-like and I have a serious bronchitis" (GP6, male, 50y- P21, male, 31y, URTI)]. The suggested diagnosis sounded more like a label or vernacular name that patients used to show familiarity with these types of symptoms than an understanding of whether the cause was viral or bacterial.

Most patients spontaneously specified and legitimized the reason for the encounter at the start of the consultation. Patients set the context that influenced their decision to consult, such as going on holidays, work obligations, need for a sick note, being referred by a worried family member/partner, or the unavailability of their regular GP. Sometimes, but not always, these reasons implicitly contained the reason why the patient consulted $\mathrm{OOH}$. Additionally, reasons related to the illness, such as worsening of symptoms, asking for medication, or being worried about a symptom were observed. Some examples are shown in Table 3. Often, the introductory talk already indicated some of the underlying ICE of the patients, but these were often not explicitly mentioned by the patient nor explored by the GP. When delivering the diagnosis, most GPs referred back to the (assumed) ICEs.

In only two out of the 77 consultations, two different GPs explicitly elicited the reason why the patient decided to consult the GP on call during the weekend.

The way some patients formulated their reason for encounter sounded as if visiting the GP would alter the course of their illness. For example, a patient expressed the idea that by going to the doctor (and expecting a treatment?), they would prevent the illness from getting worse. Some patients have had a previous 
TABLE 2 | Characteristics of the general practitioners (GPS), patients, and consultations.

\begin{tabular}{lc}
\hline GP characteristics & \\
Number of participating GPs & 19 \\
Age in years of GPs & $42.47(13.41)$ \\
Mean (SD) & 39 \\
Median & $26-64$ \\
Range (min-max) & \\
Years in practice & $14.7(12.42)$ \\
Mean (SD) & 12 \\
Median & $1-38$ \\
Range (min-max) & $7(37 \%)$ \\
Gender distribution of GPs & $12(63 \%)$ \\
Male & \\
Female &
\end{tabular}

Type of GP practice they work in during regular office hours (outside OOH care)

$2(10.5 \%)$

Duo

$1(5.3 \%)$

Group

$15(78.9 \%)$

Community health centre

$1(5.3 \%)$

$2(/ 19)$

Duration of the consultations in hh:mm:ss

Mean (SD)

Median

$00: 12: 19(00: 05: 13)$

$00: 11: 21$

Range (min-max)

Consultations per GP

Mean (SD)

Median

Range (min-max)

Patient characteristics

Number of participating patients

Age in years of patients

Mean (SD)

Median

Range (min-max)

Missing values

Gender distribution of patients

Male

Female

\section{Consultations}

Different diagnoses

Upper respiratory tract infection $\quad 31$

Otitis media/Otitis externa

Sore throat/pharyngitis/tonsillitis/uvulitis/throat

abscess

Sinusitis

Viral/flu-like illness

Tracheitis/laryngitis

Bronchitis

Pneumonia

Bronchiolitis

Lymphadenopathy

Fever

Antibiotics prescribed
00:04:24-00:30:04

4.05 (2.25)

4

1-8

77

$22.30(21.75)$

22

0-89

6

$33(43 \%)$

$44(57 \%)$

10

13

7

5

4

3

1

1

1

1

14 (4 delayed prescriptions) (18\%)

GPs, general practitioners; $\mathrm{OOH}$, out-of-hours.

experience of a serious infection and were told that they were "too late" or "just in time" so implying that timing of consultation in the course of illness has an important impact on the evolution of the illness. Table 4 shows some examples.

\section{How GPs Elicit the Perspective of the Patients}

There were differences between GPs in how much time they gave patients for their problem presentation. The GPs with an empathic open attitude, who gave space to talk and present the problem, who made eye contact and did not immediately start typing, who picked up cues and asked open questions and made encouraging sounds, spontaneously received a lot of information about the ICE of the patients. Some GPs explicitly elicited the ICE at the start of the consultation. But also in these consultations, we still observed other ICEs popping up later in the consultation, for example during the clinical examination or the management phase.

Two discrepant consultation styles showed one GP who created plenty of space for the perspective of the patients and a second GP who often interrupted the patient without attention to the agenda of the patient. The open communication and understanding of the concerns and expectations of the patient in the former GP, led, in one case, to a (most likely) unnecessary delayed antibiotic prescription (also see Delayed Prescribing to Meet Patient Expectations?). The latter GP both asked closed questions and completed the history taking much faster. She also communicated her immediate decision not to prescribe antibiotics much more directly to the patient, not leaving any space for the patient to protest. We added more detailed analysis of this interaction and comprehensive excerpts of these two different GP styles as Supplementary Material 2.

\section{How GPs Address the Concerns of Patients}

Patients did not always explicitly mention concerns nor did the GP elicit them. Only two GPs actively probed if the patient was concerned, of which one GP routinely asked it during all her consultations. The GPs addressed possible concerns throughout the clinical examination by commenting out loud on what they saw/heard or not and explained why this reassured or worried them. Often, GPs summarized their clinical findings when explaining the diagnosis and used them to explain why they did or did not prescribe antibiotics. They explained to the patient that they were not worried, for example, because the lungs sounded clear, the ears were not that red, the throat looked ok, and so on, that it looked like a viral infection, and there was no need for antibiotics. If they did prescribe an antibiotic, they expressed their concerns about certain symptoms and justified the antibiotic prescription.

If the GP did not address the concerns of the patients, the patients often mentioned them again later on in the consultation. We noticed that not addressing the concerns made it more difficult for the GP to "defend" a non-antibiotic management strategy. In the following example, there was an indirect resistance by a mother, who was concerned about her baby girl with fever and cough. The GP tried to reassure her by saying that it was "just an airway infection." However, after this fragment, 
TABLE 3 | Reasons to visit and possible ideas, concerns, and expectations (ICEs) during out-of-hours $(\mathrm{OOH})$ care.

$\begin{array}{ll}\begin{array}{l}\text { Reasons to visit the Example } \\ \mathrm{OOH}\end{array} & \begin{array}{l}\text { Other reasons or ICEs prompted in the consultation by the } \\ \text { patient }\end{array}\end{array}$

\section{$\mathrm{OOH}$}

\section{Leaving for} vacation/holiday /work next day

\author{
$P$ : the reason I come now instead of waiting until Monday is \\ because I have to fly on Monday so I want to know if I should \\ or not... (GP6, male, 50y- P21, male, 31y, URTI)
}

Sent by family member/partner
Double consultation as two people in the household are ill

Regular GP not available/ Need of a sick note

Worsening of symptoms

Asking for medication

Worried about a symptom
P: well I think I've got one of these typical airway infections but my wife said if you can't swallow properly you have to have it checked out, to see it's not an angina (GP16, female, 28y - P61, male, 38y, sore throat)

P: so I thought I will go anyway (0.4) I will let him get checked and then me because I feel even more ill (GP11, female, 39y - P36 male, 3y, URTI)

P: I have been in bed with the flu for a few days, but I have to work tomorrow, I'm not up for it, and in the Netherlands they are very accommodating but in Belgium.......

P: My GP couldn't see me anymore today (0.2) so I thought ... (GP8, female, 28y - P26, male, 21y, URTI)

Mother: It has been a few days now that he's got an airway infection and now this morning he said this night he really was in pain (GP16, female, 28y - P60, male, 6y, otitis) $\mathrm{P}$ : I went to the pharmacy (.) three days ago GP: oh yes (looks at the medication) P: and I picked up this but it's not really working GP: no? P: it's more like candy (GP13, female, 29y - P46, male, $74 \mathrm{y}$, tracheitis/laryngitis)

\section{Mother: what should we do? because I see a lot of white spots in} her throat (GP17, female, 51y - P64, female, 26y, sore throat)
To have a thorough clinical examination
Mother: yes, she had a heavy cold just recently so the question is to examine her again thoroughly (GP13, female, 29y - P44, female, <1y, URTI)
P: I'm really flu-like and I have a serious bronchitis. ... I think it's because of the air conditioning in the airplane.

...

I don't often take medication. It has to be really bad then.

...

Last time I had this kind of cough, I let it go on too long and then I came to the doctor and he said I had a bad pneumonia. So I didn't want that this time.

GP: ok, and it was cured with?

$P$ : yes, just with some antibiotics, and then it was better

I just came back from the States, yes busy life

...

and then l'm getting married

...

GP: And a jet lag?

$P$ : a jet lag, yes, but I can handle that pretty well

...

If I can work? I work with clients, one on one, because I don't want to make anyone else sick

$\mathrm{P}$ : I have taken paracetamol, it helps against the muscle strain, headache, but not against the pain when I swallow,

...

It started on Friday, and now it's Sunday, I still suffer from it... paracetamol makes it bearable, but if I don't take it I almost can't swallow.

...

During clinical examination:

-I recently took antibiotics for a tick bite. So I think my body is just too weak in general

P: I can't swallow well, even my own saliva hurts, and also when I'm eating and drinking

and I'm pregnant too

During clinical examination:

P: yes, I've also had mononucleosis

GP: yes?

P: actually a year now

...

$\mathrm{P}$ : and I also have the idea that it is a bit more difficult in terms of immunity

- M: when he complains, something is really going on

- euh and we will soon leave for Legoland so that's why I eum

- yes I just wanted to check

$P$ : I think I have a throat infection

- but I also have a strong cough, less during the day now, but at night and in the morning I really have to cough a lot

P: It's an awful lot of pain when I swallow and talk

- I went to work yesterday, it was ok, but around noon I took some pain-killers because I was so in so much pain

- But I am not someone who takes painkillers quickly, I will say that

M: now our grandson normally comes tomorrow,

what would we do?

$P$ : And then I also had antibiotics and since then I have been terrified about these. The following week I had sores all over my mouth.

$\mathrm{M}$ : 3 days ago she got her vaccinations as well

- She has been going to day care for a while and she has had such a strong cold several times, with a cough. And then, um, for her nose, yeah, what was that actually called 
TABLE 3 | Continued

\begin{tabular}{|c|c|c|}
\hline $\begin{array}{l}\text { Reasons to visit the } \\
\text { OOH }\end{array}$ & Example & $\begin{array}{l}\text { Other reasons or ICEs prompted in the consultation by the } \\
\text { patient }\end{array}$ \\
\hline & & $\begin{array}{l}\text { but for the day care they only wanted to give it, if you have a prescription. } \\
\text { - and I had already been to the doctor twice, and the doctor said by } \\
\text { phone: yes, give her the drops } \\
\text { - especially whiny, but it is not too bad. She's a really super happy baby, } \\
\text { so } \\
\text { During clinical examination: } \\
\text { She is ok on the curve they said. But she is, she only weighs } 5.2 \text { kilos } \\
\text { or so }\end{array}$ \\
\hline
\end{tabular}

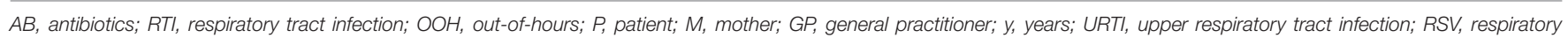
syncytial virus.

the GP acknowledged that children could be very ill from a viral infection, she gave safety-netting advice and explained why she is not worried and at that point, the mother accepted the treatment plan.

\section{GP: I don't think this is something we} should give antibiotics for

I think if we give antibiotics I don't expect it will get better spectacularly I don't expect that at all. (GP starts typing)

GP: So I really think it's just (0.5) an airway infection and that you have to sweat it out Mother: It looks so heavy then. (GP frowns) Mother: but if you don't see anything like that, well

Mother to the child (smirky tone): well (.) you're completely fine then

GP: No, no, she does have an infection, there is indeed something wrong Mother: yes because she has a fever GP: yes, indeed, but not everyone makes high fever, there are people with the same infection who will not have 39 degrees fever.

Mother: yes

And uh uh

When should I go back to the doctor or already-

within a day or two?

GP: if she still has a fever on Tuesday I would have her checked by a doctor again, to check her ear

Mother: yes

GP: if that has gotten worse um

If pus runs out of the ear(.)

I would also take her to the doctor

If- if her intake is not ok, if feeding and

drinking does not go well

If she's getting short of breath

Mother: yes

GP: <but at this point we see nothing

like that $>$

Mother: ${ }^{\circ}$ no
GP delivers the diagnosis with a non-antibiotic treatment plan.

The GP uses the term "just an airway infection" and there is no treatment necessary, which seems to minimize the symptoms.

The mother shows resistance. She uses the word "well" and expresses this by saying in a sarcastic tone that there is nothing wrong with you to the child.

The GP acknowledges the mother in the fact that the child is sick. She tries to give reassurance about the fever.

The mother asks about when there is a need to reconsult. The GP gives detailed safety netting advice.
Mother: but that cough-

GP: yes (doctor nods), but her lungs

sound fine, so l'm not worried

Mother: ok, thank you

GP: so keep an eye on her

but you are doing well

$>$ be sure to rinse her nose so there is

as little pressure as possible on the

ear $<$

But otherwise

Mother: yes yes yes

(GP5, female, 38y - P14, female, 2y, URTI).

\section{Expectations}

We explored how GPs and patients communicated about what help the patient expected for the problem. Clear patient expectations led to smooth and straightforward consultations. And we observed how delayed prescribing was used to meet patient expectations for antibiotics.

\section{Clear Patient Expectations and Straightforward Consultation}

In general, GPs nor patients in this study talked directly about their expectations from the consultation and none of the GPs elicited the view of the patients about receiving antibiotics. Asking if the patient had to work that day and if they needed a sick note, was commonly used as an indirect way to clarify the expectations of the visit of the patients. Several patients spontaneously explained to the GP that they needed a sick note and that this was their reason for the encounter. This is generally followed by a straightforward consultation without any prescriptions.

\section{Delayed Prescribing to Meet Patient Expectations?}

Four patients received a delayed antibiotic prescription. In two cases, the GP prescribed the antibiotic after the patient questioned the non-antibiotic decision explicitly. These patients used different strategies to negotiate an antibiotic prescription. One patient prepared the antibiotic prescription by presenting himself as a person who would not just take antibiotics if it is not necessary. He said he was "not a big fan of antibiotics" and "he 
TABLE 4 | Examples of patients who imply that visiting their GP will alter the course of their illness.
P: I don't have any fever now

but I think tonight I will have a seriously high fever

(GP13, female, 29y, P47, male, 48y, viral/flu-like illness)

$P$ : a lot of snot

a bit of cough

GP: a little cough?

$P$ : a little

(GP starts typing)

$\mathrm{P}$ : nothing else (0.3) no

(0.5)

GP: yes

$\mathrm{P}$ : but in the past

Euh 2 years ago

I had a pneumonia

so that's why

(GP18, female, 46y, P70, female, 40y, URTI)

$P$ : I guess It's all not that bad

but I thought, if I don't go now, it probably will get worse

and mostly the ear bothers me

(GP11, female, 39y - P37, female, 42y, URTI)

$\mathrm{P}$ : and I thought euhm I will go to the practice, here

because l'm afraid it could become a throat infection

euhm, but I don't make any fever so

(GP15, female, 36y -P55, male, adult, tracheitis/laryngitis)

GP: Do you have health issues we should know of? Of the respiratory tract?

P: No. Last time I had this kind of cough, I let it go on too long and then I came to the doctor and he said I had a bad pneumonia. So I didn't want that this time.

GP: how long ago was it?

$P$ : three, 4 years ago, something like that

GP: ok, and it was solved with?

$\mathrm{P}$ : yes, just with some antibiotics, and then it became better.

(GP6, male, 50y - P21, male, 31y,URTI)

P, patient; GP, general practitioner; y, years URTI, upper respiratory tract infection.

had received a delayed prescription in the past and did not collect it." Although the GP first clearly explained why antibiotics are not necessary, he issued a delayed prescription after the patient questioned his decision ("But no antibiotics?"). We included an excerpt of this consultation and discuss the observed interaction in Supplementary Material 2.

The other patient used the argument that in her experience her regular GP does not offer an antibiotic prescription at the first consult for her child, but that she always needs to go back as the child gets worse without antibiotics.

\section{Non-antibiotic Management Plan}

After the clinical examination, the GP communicated the diagnosis and a treatment plan.

\section{Non-antibiotic Management Plan Well-Accepted}

In most cases, the GP gave the diagnosis after the clinical examination, and this statement was immediately followed by a non-antibiotic management plan. In many cases, the GPs literally indicated that there was no indication for antibiotics. Often this information was combined with some reassuring elements of the

clinical examination or the absence of alarm symptoms, such as in the following excerpt.

GP: it actually all looks good
$P$ : yes

GP: sorry, that's very frustrating but sometimes things like this can take 2 weeks

$P$ : yes

GP: it is still-for me- no indication for antibiotics

it's also better for your own body to overcome this.hh

$P$ : yes

GP: but I would definitely do, is rinse your nose and use a nasal spray because-

(GP2, female, 26y, P6, female, 27y, URTI).

In limited cases, the patients asked if they needed an antibiotic immediately after the GP explained the diagnosis. When a GP clarified why antibiotics were not needed, most patients accepted this decision as shown in the following consultation.

$\mathrm{P}$ : so the diagnosis is?

GP: yes, I think it's just a viral infection

$P$ : yes, a lot of people

GP: yes, there are a lot of people flu-ish

this week. Well okay, it's not the flu yet,

but feverish-

$P$ : yes I am too, it really feels like,

cold-warm, cold-warm all the time. I

don't know, l'm sweating so hard. So, yes, that's how I feel

GP: yes, yes. But you can't do more than recuperate a bit. You already have, you have all the home remedies that you need. Euhm, I can't really add, euhm, yeah, take it easy for a few days P: but definitely no antibiotics?

GP: no, it looks very much like a viral infection. That's also how your throat looks, huh: your throat looks very red $P$ : ah ok

(GP11, female, 39y, P37, female, 42y, URTI).

In only one out of the 77 consultations, the non-antibiotic treatment plan evoked a conflict with a patient, but the GP did not budge. In this consultation an expectation for an antibiotic was not explicitly explored by the GP, but could have been assumed in the following interaction:

GP: and you're here because you say the medication doesn't work that well?

P: no no you need to give me good medication

Cause I know that-

that if it helps (.) it can't get any worse (0.6)

if it works, the medicine 
After the physical examination, the patient clearly indicated that he expected and needed an antibiotic. Although the GP at that point used different communication techniques (reflection of feelings, acknowledging the seriousness of the complaints, explaining why antibiotics are not necessary, providing a symptomatic alternative, and so on) to persuade the patient, the resistance lasted until the end of the consultation. The patient and GP in this case had different ethnic roots. So possibly, this consultation was complicated by cultural differences and the use of a non-native language by both the GP and the patient. We provided a more comprehensive excerpt and analysis of the interaction of this consultation in Supplementary Material 3.

Many GPs offered non-antibiotic management wrapped in the narrative "it is a viral infection, antibiotics won't help," which was well-accepted by most patients. In one case a patient replied he did not expect an antibiotic, in another, a patient talked about a previous serious side-effect of the antibiotics and would prefer not to take antibiotics. In the following example, parents consulted the GP before traveling to India because they did not want to receive antibiotics unnecessarily and they had more trust in the Belgian doctors.

\author{
GP: I don't know if you have euh over there you have the possibility \\ of medical $=$ \\ Father: =yes yes, we have we have \\ I just think the only problem in India is that the doctors give \\ antibiotics too quickly. \\ GP: ah ha \\ Father: and I, yeah, we don't want to do so \\ that's my only concern \\ and that's why we always bring our child to the doctor here \\ (GP9, male, 42y - P27, male, 3y, URTI)
}

\section{Discussing the Treatment Plan}

Sometimes "antibiotics" were not explicitly mentioned, but GPs used phrases such as: "We can't do anything" or "not to use a cannon (to kill a flea)," as shown in the examples in Table 5.

The GPs addressed expectations about medication prescriptions when they were discussing the treatment plan. If certain undiscussed expectations were not met, patients would bring these up themselves. For example: "no coughing syrup?," "no throat spray?" Some GPs discussed these expectations and the needs of the patients before prescribing, and they explained the reasons for not choosing a certain treatment.

\section{DISCUSSION}

In this study, we examined how patients with RTI present their complaints to $\mathrm{OOH}$ primary care and how GPs interact with them. Patients with RTIs mostly start a consultation by listing symptoms and/or suggesting a possible diagnosis (28). Stivers et al. showed that parents from children using a bacterial candidate diagnosis instead of a description of their symptoms were more likely indexed by the physician as expecting an antibiotic, but Cabral et al. found that parents rarely implied an expectation for antibiotics for children with RTI and there was no relationship with the antibiotic prescribing of GPs. Globally, the
TABLE 5 | How GPs explain self-limiting disease/medication is not necessary.

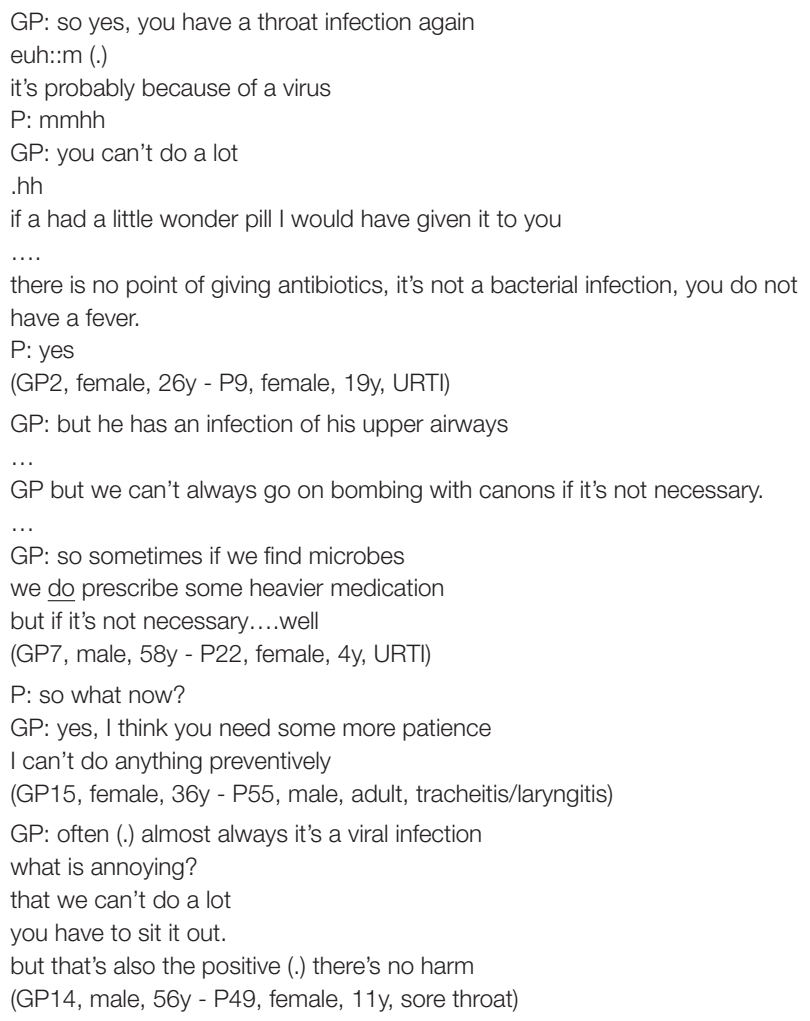

P, patient; GP,general practitioner; y, years.

trend of patient expectation for receiving antibiotics for RTIs is declining (54), but still, the problem of overprescribing remains due to many patient- and doctor-related reasons, such as lack of time, pleasing, perceived severity, and so on but also due to the health care system and the overall culture (55-57).

Patients give different reasons for their decision to consult the GP during OOH. This could be interpreted as a justification or legitimations for the consultation, in the literature also described as "doctorability" (18). Almost none of the GPs elicit specifically why the patients choose to consult $\mathrm{OOH}$ (this could reveal a lot of the ICE of the patients) keeping the actual reason for the encounter implicit. They do not actively ask patients about their views on antibiotics and seldom explore other expectations. Eliciting patient expectations for an antibiotic has been proposed as an intervention to reduce inappropriate antibiotic prescribing $(58,59)$. Other studies have shown that expectations are seldom directly discussed $(60,61)$. We found that exploring the ICE of patients is not commonly done for RTIs in Belgian $\mathrm{OOH}$ primary care. Conversely, Lemiengre et al. have shown that eliciting parental concerns can potentially increase antibiotic prescribing (62). Indeed, making space for the agenda of the patients, also creates a potential pitfall when empathy is confused with yielding to inappropriate treatment decisions in response to very present ICE. This can lead to unnecessary antibiotic prescriptions, as we have illustrated with a few deviant cases. The MAAS Global manual explicitly states that the GP's indulgence in content is not a characteristic of empathy (53). 
Research shows that active listening and addressing the ICE of patients leads to higher patient satisfaction and fewer follow-up consultations (22). But there is often an infrequency in soliciting the full range of the concerns of patients (63), as we could confirm in our study. ( $\mathrm{Re}$ ) consultation is one of the high-risk factors of receiving an antibiotic, and therefore, optimizing doctor-patient communication could affect antibiotic prescribing. Addressing the health belief that a GP influences the evolution of infection and educating patients on the natural evolution of infections and self-treatment could have an impact on (re)consultations in the future as well. Especially in $\mathrm{OOH}$ primary care where non-urgent problems could better be seen by the regular GP.

The narrative "it's a viral infection, you don't need an antibiotic" confirms the dichotomized thinking of GPs during consultations of RTIs (bacterial vs. viral infection/antibiotics vs. no antibiotics) (31) and also ignores the fact that bacterial infection does not always benefit from antibiotics. GPs seem to assume that the reason a patient visits the GP on call with an RTI, amongst others, is receiving an antibiotic, by delivering the diagnosis directly linked to the non-antibiotic management plan, which is well-accepted by patients. At this point in the consultation-after the history taking and physical examination-GPs have sufficient arguments to back up their diagnosis and to argue whether antibiotics are necessary or not. It is recommended to elicit the ICE early in the consultation. But, without information from the physical examination, it is more difficult to discuss a possible antibiotic expectation already at that point. In an Irish study using questionnaires, one in three patients attending $\mathrm{OOH}$ with acute RTI symptoms expected to receive antibiotics before the consultation (34). Only patients hoping for antibiotics are less satisfied, when not prescribed an antibiotic (not the ones expecting or asking antibiotics) (64-67).

GPs who make room for the story of patients by using active listening techniques spontaneously receive more information about the ICE. Patients do not always explicitly talk about their concerns, but GPs use their findings of the clinical examination to reassure patients that there is no reason to give antibiotics. Some GPs ask patients what they need or what symptoms bother them the most and show a nice example of shared decision-making in prescribing symptomatic medication or self-treatment. A refocus from "we can't do anything" to informed shared decisionmaking about what the patient needs, could help $(68,69)$. Other communication tools, such as safety-netting, could be helpful in communicating when to (re)visit a GP and educating patients for following episodes. Also, triage and postponed care to the regular GP during office hours could lead to fewer RTIs presented to $\mathrm{OOH}$ primary care (10).

We saw that assumed or expressed expectations for antibiotics can lead to a delayed antibiotic prescription even though antibiotics were not clinically necessary. Delayed prescribing has been proposed as an intervention to reduce antibiotic prescribing (70). GPs in one interview study, talked about the use of delayed prescribing as a way not to jeopardize the doctor-patient relationship (71). In another interview study, it is shown that different GPs use delayed antibiotic prescribing in different ways, one of which is maintaining a good relationship to retain patients (72). But in an $\mathrm{OOH}$ setting, with no long-term relationship with the patient, this argument should play less. An established trusted relationship, which you do not have in $\mathrm{OOH}$ primary care, could help to use delayed prescriptions because the GP can estimate if a patient will follow the instruction of the GP and has sufficient understanding and if the GP can transfer the final decision onto the patient (72). In a previous interview study in the $\mathrm{OOH}$ primary care context, elements such as pleasing, reciprocity or time-pressure also played a role in the antibiotic prescribing decision (11).

\section{Strengths and Limitations}

Our video recordings captured real-life GP behavior and doctorpatient communication. It enabled us to collect rich relevant data from a broad range of different GPs, patients, and RTIs. The use of this type of data collection is rather recent and not yet applied on a large scale, contributing substantially to research on this topic. We used well-established communication models as a framework to analyze the consultations. The MAAS global has been proven effective in communication skills training to lead to more prudent prescribing of antibiotics for URTIs (73).

Triangulation with researchers from different backgrounds enhanced trustworthiness. To assess transferability, we clearly described our participants and the context in which this study took place, namely Belgian $\mathrm{OOH}$ primary care, which is a high prescribing context, with a fee-for-service system and no triage.

The GPs and patients were aware of the fact that antibiotic prescribing was our focus, and this could have influenced their communication and prescribing behavior, the so-called Hawthorne effect. Although GPs fed back that their recorded consultations reflected their normal consultation style (49), our participants could be low prescribers adhering more to the guidelines. Therefore, what we observed could be best practices. We could not objectively judge if a decision to prescribe an antibiotic was medically justified. Possibly some patients declined to participate because they were afraid not to receive antibiotics. All these elements could explain the rather low antibiotic prescribing rate we observed. Although this limitation must be recognized, it did not impede the study of communicative patterns which was the focus of the analysis.

Unfortunately, we were not able to analyze the non-verbal communication of the patients (49). We also performed a more explorative analysis. Other analyses, such as conversation analysis, could lead to more in-depth knowledge of certain patterns of interaction.

This study was performed before the COVID-19 pandemic. The meaning of the phrase "it's just a viral infection, you don't need to worry" has changed dramatically and could nowadays have a different effect on patients.

\section{CONCLUSION}

This study in $\mathrm{OOH}$ primary care shows that the actual reason for encounters for a patient with an RTI often remains implicit. However, when giving empathic attention to the story of the patients, many of the ICE of the patients appear spontaneously and this could help to tailor the communication 
about non-antibiotic decisions, educate patients about the selflimiting aspect of RTIs, and to improve patient satisfaction. Delayed antibiotic prescribing is sometimes used to meet the patient expectation for antibiotics and to safeguard the doctorpatient relationship. In clinical practice, attention to high-quality doctor-patient communication when explaining the diagnosis and treatment plan seems as important as exploring the reason for encounter and ICE to reduce antibiotic prescribing. Communication skills training has been proven to improve antibiotic prescribing in primary care during office hours. Future research could focus on implementing communication strategies to enhance prudent antibiotic prescribing for RTIs in $\mathrm{OOH}$ primary care.

\section{DATA AVAILABILITY STATEMENT}

The datasets presented in this article are not readily available because the data are not publicly available due to restrictions, it contains information that could compromise the privacy of our research participants.

\section{ETHICS STATEMENT}

The studies involving human participants were reviewed and approved by Ethics Committee of the Antwerp University Hospital/University of Antwerp. Written informed consent to participate in this study was signed by the participating GPs, the patients and for children by the legal guardian.

\section{AUTHOR CONTRIBUTIONS}

AC: conceptualization, data curation, formal analysis, investigation, methodology, project administration,

\section{REFERENCES}

1. Colliers A, Adriaenssens N, Anthierens S, Bartholomeeusen S, Philips H, Remmen R, et al. Antibiotic prescribing quality in out-of-hours primary care and critical appraisal of disease-specific quality indicators. Antibiotics. (2019) 8:79. doi: 10.3390/antibiotics 8020079

2. Cronberg O, Tyrstrup M, Ekblom K, Hedin K. Diagnosis-linked antibiotic prescribing in Swedish primary care-a comparison between in-hours and outof-hours. BMC Infect Dis. (2020) 20:1-11. doi: 10.1186/s12879-020-05334-7

3. Lindberg BH, Gjelstad S, Foshaug M, Høye S. Antibiotic prescribing for acute respiratory tract infections in Norwegian primary care outof-hours service. Scand J Primary Health Care. (2017) 35:178-85. doi: 10.1080/02813432.2017.1333301

4. Debets VE, Verheij TJ, van der Velden AW. Antibiotic prescribing during office hours and out-of-hours: a comparison of quality and quantity in primary care in the Netherlands. Br J Gene Practice. (2017) 67:e178-86. doi: 10.3399/bjgp17X689641

5. Palsdottir HA, Jonsson JS, Sigurdsson EL. Prescriptions of antibiotics in outof-hours primary care setting in Reykjavik capital area. Scand J Primary Health Care. (2020) 38:265-71. doi: 10.1080/02813432.2020.1794159

6. Hayward GN, Fisher R, Spence G, Lasserson D. Increase in antibiotic prescriptions in out-of-hours primary care in contrast to in-hours primary care prescriptions: service evaluation in a population of 600 000 patients. J Antimicrob Chemother. (2016) 71:2612-9. doi: 10.1093/jac/ dkw189 writing-original draft, review, and editing. KB: formal analysis, methodology, writing-review, and editing. HP: supervision, writing-review, and editing. RR and SC: supervision, funding acquisition, writing-review, and editing. SA: conceptualization, formal analysis, methodology, supervision, writing-review, and editing. All authors contributed to the article and approved the submitted version.

\section{FUNDING}

This study was part of the BAbAR study and has been granted a PhD fellowship by the Faculty of Medicine and Health Sciences of the University of Antwerp. The funder had no involvement in any of the research stages.

\section{ACKNOWLEDGMENTS}

We would like to thank the participating GPs and patients for their time and effort and the board of the Antwerp GPC Brabo for their very helpful collaboration.

\section{SUPPLEMENTARY MATERIAL}

The Supplementary Material for this article can be found online at: https://www.frontiersin.org/articles/10.3389/fmed. 2021.735276/full\#supplementary-material

Data Sheet 1 | Supplementary Material 3. Conflict about non-antibiotic decision.

Data Sheet 2 | Supplementary Material 2. How GPs elicit the patients' perspective: Two different approaches.

Data Sheet 3 | Supplementary Material 1. Analysis framework.
7. Edelstein M, Agbebiyi A, Ashiru-Oredope D. Trends and patterns in antibiotic prescribing among out-of-hours primary care providers in England, 2010-14. J Antimicrob Chemother. (2017) 72:3490-5. doi: 10.1093/jac/dkx323

8. Christensen MB, Nørøxe KB, Moth G, Vedsted P, Huibers L. Drug prescriptions in Danish out-of-hours primary care: a 1-yearpopulationbased study. Scand J Primary Health Care. (2016) 34:453-8. doi: 10.1080/02813432.2016.1248622

9. Keizer E, Smits M, Peters Y, Huibers L, Giesen P, Wensing M. Contacts with out-of-hours primary care for nonurgent problems: patients' beliefs or deficiencies in healthcare? BMC Family Practice. (2015) 16:157. doi: 10.1186/s12875-015-0376-9

10. Smits M, Colliers A, Jansen T, Remmen R, Bartholomeeusen S, Verheij R. Examining differences in out-of-hours primary care use in Belgium and the Netherlands: a cross-sectional study. Eur J Public Health-Oxford. (2019) 29:1018-24. doi: 10.1093/eurpub/ckz083

11. Colliers A, Coenen S, Remmen R, Philips H, Anthierens S. How do general practitioners and pharmacists experience antibiotic use in outof-hours primary care? An exploratory qualitative interview study to inform a participatory action research project. BMJ Open. (2018) 8:e023154. doi: 10.1136/bmjopen-2018-023154

12. Williams SJ, Halls AV, Tonkin-Crine S, Moore MV, Latter SE. General practitioner and nurse prescriber experiences of prescribing antibiotics for respiratory tract infections in UK primary care out-of-hours services (the UNITE study). J Antimicrobial Chemother. (2018) 73:795-803. doi: $10.1093 / \mathrm{jac} / \mathrm{dkx} 429$ 
13. Scott JG, Cohen D, Dicicco-Bloom B, Orzano AJ, Jaen CR, Crabtree BF. Antibiotic use in acute respiratory infections and the ways patients pressure physicians for a prescription. J Family Pract. (2001) 50:853.

14. Stivers T. Participating in decisions about treatment: overt parent pressure for antibiotic medication in pediatric encounters. Soc Sci Med. (2002) 54:1111-30. doi: 10.1016/S0277-9536(01)00085-5

15. Stivers T, Mangione-Smith R, Elliott MN, McDonald L, Heritage J. Why do physicians think parents expect antibiotics? What parents report vs what physicians believe. J Family Pract. (2003) 52:140-7.

16. Zhou, Y, MacGeorge EL, Hackman N. Parent-provider communication and antibiotic prescribing for pediatric ear infections. Commun Res Rep. (2019) 36:170-8. doi: 10.1080/08824096.2019.1586666

17. Heritage J, Robinson JD. The structure of patients' presenting concerns: physicians' opening questions. Health Commun. (2006) 19:89-102. doi: 10.1207/s15327027hc1902_1

18. Heritage J, Robinson JD. Accounting for the visit: Giving reasons for seeking medical care. Stud Int Sociolinguistics. (2006) 20:48. doi: 10.1017/CBO9780511607172.005

19. Robinson JD. An interactional structure of medical activities during acute visits and its implications for patients' participation. Health Commun. (2003) 15:27-59. doi: 10.1207/S15327027HC1501_2

20. Gobat N, Kinnersley P, Gregory J.W, Robling M. What is agenda setting in the clinical encounter? Consensus from literature review and expert consultation. Patient Educ Counsel. (2015) 98:822-9. doi: 10.1016/j.pec.2015.03.024

21. Norfolk T, Birdi K, Walsh D. The role of empathy in establishing rapport in the consultation: a new model. Med Educ. (2007) 41:690-7. doi: 10.1111/j.1365-2923.2007.02789.x

22. Silverman J, Kurtz S, Draper J. Skills for Communicating With Patients. New York, NY: CRC Press (2016). doi: 10.1201/9781910227268

23. Kurtz SM, Silverman JD. The Calgary-Cambridge Referenced Observation Guides: an aid to defining the curriculum and organizing the teaching in communication training programmes. Med Educ. (1996) 30:83-9. doi: 10.1111/j.1365-2923.1996.tb00724.x

24. Wanzer MB, Booth-Butterfield M, Gruber K. Perceptions of health care providers' communication: relationships between patient-centered communication and satisfaction. Health Commun. (2004) 16:363-84. doi: 10.1207/S15327027HC1603_6

25. King A, Hoppe RB. "Best practice" for patient-centered communication: a narrative review. J Graduate Med Educ. (2013) 5:385. doi: 10.4300/JGME-D-13-00072.1

26. Robinson JH, Callister LC, Berry JA, Dearing KA. Patient-centered care and adherence: Definitions and applications to improve outcomes. J Am Acad Nurse Pract. (2008) 20:600-7. doi: 10.1111/j.1745-7599.2008.00360.x

27. Spence D. Falling through the ICE. BMJ. (2009) 338:b5. doi: $10.1136 / \mathrm{bmj} . \mathrm{b5}$

28. Stivers T. Presenting the problem in pediatric encounters: "Symptoms only" versus "candidate diagnosis" presentations. Health Commun. (2002) 14:299338. doi: 10.1207/S15327027HC1403_2

29. Rollnick S, Seale C, Rees M, Butler C, Kinnersley P, Anderson L. Inside the routine general practice consultation: an observational study of consultations for sore throats. Family Practice. (2001) 18:506-10. doi: 10.1093/fampra/18.5.506

30. Stivers TJ. Negotiating Antibiotic Treatment in Pediatric Care: The Communication of Preferences in Physician-Parent Interaction. Los Angeles, CA: University of California (2000).

31. Colliers A, Coenen S, Bombeke K, Remmen R, Philips H, Anthierens S. Understanding general practitioners' antibiotic prescribing decisions in outof-hours primary care: a video-elicitation interview study. Antibiotics. (2020) 9:115. doi: 10.3390/antibiotics9030115

32. O'Doherty J, Leader LF, O'Regan A, Dunne C, Puthoopparambil SJ, O'Connor R. Over prescribing of antibiotics for acute respiratory tract infections; a qualitative study to explore Irish general practitioners' perspectives. BMC Family Pract. (2019) 20:27. doi: 10.1186/s12875-019-0917-8

33. Huibers L, Carlsen AH, Moth G, Christensen HC, Riddervold IS, Christensen MB. Patient motives for contacting out-of-hours care in Denmark: a cross-sectional study. BMC Emerg Med. (2020) 20:20. doi: 10.1186/s12873-020-00312-3

34. O’Connor R, O'Doherty J, O’Regan A, O’Neill A, McMahon C, Dunne CP. Medical management of acute upper respiratory infections in an urban primary care out-of-hours facility: cross-sectional study of patient presentations and expectations. BMJ Open. (2019) 9:e025396. doi: 10.1136/bmjopen-2018-025396

35. O'Connor R, O’Doherty J, O'Regan A, Dunne C. Antibiotic use for acute respiratory tract infections (ARTI) in primary care; what factors affect prescribing and why is it important? A narrative review. Irish J Med Sci. (2018) 187:969-86. doi: 10.1007/s11845-018-1774-5

36. Mortazhejri S, Patey AM, Stacey D, Bhatia RS, Abdulla A, Grimshaw JM. Understanding determinants of patients' decisions to attend their family physician and to take antibiotics for upper respiratory tract infections: a qualitative descriptive study. BMC Family Pract. (2020) 21:1-11. doi: 10.1186/s12875-020-01196-9

37. Little P, Stuart B, Francis N, Douglas E, Tonkin-Crine S, Anthierens S, et al. Antibiotic prescribing for acute respiratory tract infections 12 months after communication and CRP training: a randomized trial. Ann Family Med. (2019) 17:125-32. doi: 10.1370/afm.2356

38. Cabral C, Ingram J, Lucas PJ, Redmond NM, Kai J, Hay AD, et al. Influence of clinical communication on parents' antibiotic expectations for children with respiratory tract infections. Ann Family Med. (2016) 14:141-7. doi: $10.1370 / \mathrm{afm} .1892$

39. McNulty CA, Nichols T, French DP, Joshi P, Butler CC. Expectations for consultations and antibiotics for respiratory tract infection in primary care: the RTI clinical iceberg. Br J Gen Pract. (2013) 63:e429-36. doi: 10.3399/bjgp13X669149

40. Barry CA, Bradley CP, Britten N, Stevenson FA, Barber N. Patients' unvoiced agendas in general practice consultations: qualitative study. BMJ. (2000) 320:1246-50. doi: 10.1136/bmj.320.7244.1246

41. Britten N, Stevenson FA, Barry CA, Barber N, Bradley CP. Misunderstandings in prescribing decisions in general practice: qualitative study. BMJ. (2000) 320:484-8. doi: 10.1136/bmj.320.7233.484

42. Kravitz RL, Cope DW, Bhrany V, Leake B. Internal medicine patients expectations for care during office visits. J Gene Internal Med. (1994) 9:75-81. doi: 10.1007/BF02600205

43. Bell RA, Kravitz RL, Thom D, Krupat E, Azari R. Unsaid but not forgotten: patients' unvoiced desires in office visits. Arch Internal Med. (2001) 161:197784. doi: 10.1001/archinte.161.16.1977

44. Peltenburg M, Fischer JE, Bahrs O, van Dulmen S, Van den BrinkMuinen A. The unexpected in primary care: a multicenter study on the emergence of unvoiced patient agenda. Ann Family Med. (2004) 2:534-40. doi: 10.1370/afm.241

45. Marvel MK, Epstein RM, Flowers K, Beckman HB. Soliciting the patient's agenda: have we improved? JAMA. (1999) 281:283-7. doi: 10.1001/jama.281.3.283

46. Dyche L, Swiderski D. The effect of physician solicitation approaches on ability to identify patient concerns. J Gene Internal Med. (2005) 20:267-70. doi: 10.1111/j.1525-1497.2005.40266.x

47. Lee S-H, Kim CW. Presentation of patients' problems during triage in emergency medicine. Patient Educ Counsel. (2015) 98:578-87. doi: 10.1016/j.pec.2015.01.011

48. Colliers A, Coenen S, Philips H, Remmen R, Anthierens S. Optimising the quality of antibiotic prescribing in out-of-hours primary care in Belgium: a study protocol for an action research project. BMJ Open. (2017) 7:e017522. doi: 10.1136/bmjopen-2017-017522

49. Colliers A, Coenen S, Remmen R, Philips H, Anthierens S. Looking inside the out-of-hours primary care consultation: general practitioners' and researchers' experiences of using video observations as a method. Int J Qualit Methods. (2019) 18:1609406919879341. doi: 10.1177/1609406919879341

50. Jefferson G. Transcript notation. Struct Soc Action. (1984) 5:346-69. doi: 10.1017/CBO9780511665868.021

51. Gale NK, Heath G, Cameron E, Rashid S, Redwood S. Using the framework method for the analysis of qualitative data in multidisciplinary health research. BMC Med Res Methodol. (2013) 13:1-8. doi: 10.1186/1471-2288-13-117

52. Cabral C, Horwood J, Symonds J, Ingram J, Lucas PJ, Redmond NM, et al. Understanding the influence of parent-clinician communication on antibiotic prescribing for children with respiratory tract infections in primary care: a qualitative observational study using a conversation analysis approach. $B M C$ Family Practice. (2019) 20:102. doi: 10.1186/s12875-019-0993-9 
53. van Thiel J, Ram P, van Dalen J. MAAS-Global Manual. Maastricht: Maastricht University (2000).

54. Kianmehr H, Sabounchi NS, Seyedzadeh Sabounchi S, Cosler LE. Patient expectation trends on receiving antibiotic prescriptions for respiratory tract infections: A systematic review and meta-regression analysis. Int $\mathrm{J}$ Clin Practice. (2019) 73:e13360. doi: 10.1111/ijcp.13360

55. Borek AJ, Anthierens, S, Allison, R, Mcnulty CA. Social and contextual influences on antibiotic prescribing and antimicrobial stewardship: a qualitative study with clinical commissioning group and general practice professionals. Antibiotics. (2020) 9:859. doi: 10.3390/antibiotics9120859

56. Touboul-Lundgren P, Jensen S, Drai J, Lindbæk M. Identification of cultural determinants of antibiotic use cited in primary care in Europe: a mixed research synthesis study of integrated design Culture is all around us. BMC Public Health. (2015) 15:1-9. doi: 10.1186/s12889-015-2254-8

57. Tonkin-Crine S, Yardley L, Little P. Antibiotic prescribing for acute respiratory tract infections in primary care: a systematic review and meta-ethnography. J Antimicrob Chemother. (2011) 66:2215-23. doi: 10.1093/jac/dkr279

58. Cals JW, Butler CC, Hopstaken RM, Hood K, Dinant GJ. Effect of point of care testing for $\mathrm{C}$ reactive protein and training in communication skills on antibiotic use in lower respiratory tract infections: cluster randomised trial. BMJ. (2009) 338:b1374. doi: 10.1136/bmj.b1374

59. Little P, Stuart B, Francis N, Douglas E, Tonkin-Crine S, Anthierens $S$, et al. Effects of internet-based training on antibiotic prescribing rates for acute respiratory-tract infections: a multinational, cluster, randomised, factorial, controlled trial. Lancet. (2013) 382:1175-82. doi: 10.1016/S0140-6736(13)60994-0

60. Altiner A, Knauf A, Moebes J, Sielk M, Wilm S. Acute cough: a qualitative analysis of how GPs manage the consultation when patients explicitly or implicitly expect antibiotic prescriptions. Family Practice. (2004) 21:500-6. doi: 10.1093/fampra/cmh505

61. Mustafa M, Wood F, Butler CC, Elwyn G. Managing expectations of antibiotics for upper respiratory tract infections: a qualitative study. Ann Family Med. (2014) 12:29-36. doi: 10.1370/afm.1583

62. Lemiengre MB, Verbakel JY, Colman R, De Burghgraeve T, Buntinx F, Aertgeerts B, et al. Reducing inappropriate antibiotic prescribing for children in primary care: a cluster randomised controlled trial of two interventions. Br J Gene Practice. (2018) 68:e204-10. doi: 10.3399/bjgp18X69 5033

63. Robinson JD, Tate A, Heritage J. Agenda-setting revisited: When and how do primary-care physicians solicit patients' additional concerns? Patient Educ Counsel. (2016) 99:718-23. doi: 10.1016/j.pec.2015. 12.009

64. Welschen I, Kuyvenhoven M, Hoes A, Verheij T. Antibiotics for acute respiratory tract symptoms: patients' expectations, GPs' management and patient satisfaction. Family Practice. (2004) 21:234-7. doi: 10.1093/fampra/cmh303

65. Coenen S, Francis N, Kelly M, Hood K, Nuttall J, Little P, et al. Are patient views about antibiotics related to clinician perceptions, management and outcome? A multi-country study in outpatients with acute cough. PLoS ONE. (2013) 8:e76691. doi: 10.1371/journal.pone.007 6691
66. Coenen S, Van Royen P, Vermeire E, Hermann I, Denekens J. Antibiotics for coughing in general practice: a qualitative decision analysis. Family Practice. (2000) 17:380-5. doi: 10.1093/fampra/17.5.380

67. Coenen S, Michiels B, Renard D, Denekens J, Van Royen P. Antibiotic prescribing for acute cough: the effect of perceived patient demand. Br J Gene Pract. (2006) 56:183-90.

68. Land V, Parry R, Seymour J. Communication practices that encourage and constrain shared decision making in health-care encounters: Systematic review of conversation analytic research. Health Expect. (2017) 20:1228-47. doi: 10.1111/hex.12557

69. Coxeter P, Del Mar CB, McGregor L, Beller EM, Hoffmann TC. Interventions to facilitate shared decision making to address antibiotic use for acute respiratory infections in primary care. Cochrane Database Syst Rev. (2015) 2015:CD010907. doi: 10.1002/14651858.CD0109 07.pub2

70. Spurling GK, Del Mar CB, Dooley L, Foxlee R, Farley R. Delayed antibiotic prescriptions for respiratory infections. Cochrane Database Syst Rev. (2017) 9:CD004417. doi: 10.1002/14651858.CD00449 17.pub5

71. van der Zande MM, Dembinsky M, Aresi G, van Staa TP. General practitioners' accounts of negotiating antibiotic prescribing decisions with patients: a qualitative study on what influences antibiotic prescribing in low, medium and high prescribing practices. BMC Family Pract. (2019) 20:1-11. doi: 10.1186/s12875-019-1065-x

72. Saliba-Gustafsson EA, Röing M, Borg MA, Rosales-Klintz S, Lundborg CS. General practitioners' perceptions of delayed antibiotic prescription for respiratory tract infections: A phenomenographic study. PLoS ONE. (2019) 14:e0225506. doi: 10.1371/journal.pone.0225506

73. Strumann C, Steinhaeuser J, Emcke T, Sönnichsen A, Goetz K Communication training and the prescribing pattern of antibiotic prescription in primary health care. PLoS ONE. (2020) 15:e0233345. doi: 10.1371/journal.pone.0233345

Conflict of Interest: The authors declare that the research was conducted in the absence of any commercial or financial relationships that could be construed as a potential conflict of interest.

Publisher's Note: All claims expressed in this article are solely those of the authors and do not necessarily represent those of their affiliated organizations, or those of the publisher, the editors and the reviewers. Any product that may be evaluated in this article, or claim that may be made by its manufacturer, is not guaranteed or endorsed by the publisher.

Copyright (c) 2021 Colliers, Bombeke, Philips, Remmen, Coenen and Anthierens. This is an open-access article distributed under the terms of the Creative Commons Attribution License (CC BY). The use, distribution or reproduction in other forums is permitted, provided the original author(s) and the copyright owner(s) are credited and that the original publication in this journal is cited, in accordance with accepted academic practice. No use, distribution or reproduction is permitted which does not comply with these terms. 